Check for updates

Cite this: Mater. Adv., 2021, 2,6647

Received 8th May 2021, Accepted 29th August 2021

DOI: 10.1039/d1ma00420d

rsc.li/materials-advances

\title{
High heat resistance and good melt spinnability of a polyamide 66 containing benzene structure
}

\author{
Yuanyuan Ma, $\dagger^{\mathrm{ab}}$ Jingnan Zhang, iD $\dagger^{\mathrm{a}}$ Xinyu Cao, iD a Pengfei $\mathrm{Wu}{ }^{\mathrm{c}}{ }^{\mathrm{C}}$ Gang $\mathrm{Ye}{ }^{\mathrm{a}}$ \\ Yang Fu, ${ }^{d}$ Yafang Zhuang, ${ }^{a}$ Aiqing Zhang, ${ }^{b}$ Kun Zheng (D) *a and Yongmei Ma iD *ae
}

\begin{abstract}
A polymer based bag filter with high temperature resistance plays a key role in dust and acid gas treatment in the power industry. Currently, the polymers used for preparing filters with improved heat resistance include those with a high content of aromatic units. But the aromatic structure inevitably leads to a high melting point, which is disadvantageous for melt spinning. Here, we report a polyamide 66 and polyamide 6T copolymer (PA66-CO-PA6T) fiber with both high thermal stability and good spinnability. The retention rates of heat resistance of fibers after heat treatment at $185{ }^{\circ} \mathrm{C}$ and $200{ }^{\circ} \mathrm{C}$ were higher than $97.8 \%$ and $88.4 \%$, respectively. This high thermal stability is ascribed to the high thermal degradation activation energy $(E)$, which was confirmed by DSC, TG, and XRD characterization studies and fitting of kinetic data. PA66-CO-PA6T with good melt spinnability, high heat resistance strength and low cost is expected to be applied in high-temperature resistance filtration equipment such as bag filters, expanding the application range of PA66 materials.
\end{abstract}

\section{Introduction}

According to British Petroleum's Statistical World Energy Yearbook 2019, global electricity demand takes up to $50 \%$ of primary energy consumption. Coal remains the main fuel for electric power generation. However, coal fired power plants produce dust particles and acid gases, which are the main sources of air contamination. At present, the most competitive dust removal equipment is the bag filter. ${ }^{1}$ A bag filter is made of textile filter cloth or non-textile felt, which is used to filter the dust-gas mixture. When the dust-gas mixture enters the bag filter, the large size dust particles fall into the ash hopper due to the action of gravity. When the fine dust-gas mixture passes through the filter material, the dust is retained, so that the gas is purified. Furthermore, the bag filter should meet the requirements of high temperature resistance (generally above $200{ }^{\circ} \mathrm{C}$ ), corrosion resistance, high mechanical strength, long service life and low cost. ${ }^{2}$ Common bag filter materials are

\footnotetext{
${ }^{a}$ Institute of Chemistry, Chinese Academy of Science, Beijing 100190, China. E-mail: maym@iccas.ac.cn, zhengkunwd@iccas.ac.cn

${ }^{b}$ College of Chemical and Materials Engineering, South-Centrol University for Nationalities, Wuhan 430074, Hubei, China

${ }^{c}$ State Key Laboratory of Biobased Fiber Manufacturing Technology, China Textile Academy, Beijing 100025, China

${ }^{d}$ High \& New Technology Research Center of Henan Academy of Sciences, Zhengzhou, Henan 450002, China

${ }^{e}$ Beijing National Laboratory for Molecular Sciences (BNLMS), Beijing, 100190, China

$\dagger$ Yuanyuan Ma and Jingnan Zhang contributed equally to this work.
}

polyphenylene sulfide (PPS), polyimide (PI), polytetrafluoroethylene (PTFE) and fiberglass. ${ }^{3-6}$ However, the raw materials of most fibers are costly and the preparation processes are complex. Therefore, there is an urgent need to develop hightemperature resistant fibers at low cost and with easy processing. ${ }^{7-9}$

Polyamide 66 (PA66) fiber is an important fiber material with excellent chemical corrosion resistance, mechanical properties and abrasion resistance. ${ }^{10-14}$ However, PA66 belongs to a class of aliphatic polymers with low glass transition temperature $\left(T_{\mathrm{g}}\right)$ and melting point $\left(T_{\mathrm{m}}\right)$, which greatly limit its use in the high-temperature fields. Compared with aliphatic polyamides, semi-aromatic polyamides have better rigidity, heat resistance and dimensional stability. ${ }^{15-18}$ For example, PA6T is one of the important semi-aromatic polyamides, which is widely applied in fields requiring high temperature resistance, especially in automobile manufacturing, electronics and electrical industry. ${ }^{19,20}$ But, PA6T cannot be melted for spinning because its melting point exceeds its thermal decomposition temperature, causing difficulty in the fabrication of high-temperature resistant fabric. $^{21}$

For combining the properties of various polymers, a copolymerization or blending method is generally used. ${ }^{2-24}$ For example, Wang et al. synthesized PA6T/6 (50:50) copolymers with high content of rigid aromatic units, which show improved thermal stability and mechanical properties. ${ }^{25} \mathrm{Qu}$ et al. obtained PA6T/2T copolymer and found that the melting temperature decreased from $368{ }^{\circ} \mathrm{C}$ for PA6T to $347{ }^{\circ} \mathrm{C}$ for PA6T/2T copolymer. This is because the structure and regularity of the repeated units 
of PA2T and PA6T are greatly different and cannot form a cocrystal, resulting in the defective crystal structure of the copolymer. ${ }^{26}$ Nevertheless, rigid the aromatic structure leads to a high melting temperature of the copolymer, which makes melt spinning difficult. ${ }^{27-30}$ As far as we know, few studies have been reported on PA66 fibers with low content of benzene by melt spinning.

In this paper, PA66 with a low benzene content was obtained via the copolymerization method. By copolymerizing a small amount of PA6T (less than $20 \mathrm{wt} \%$ ) with PA66, the obtained PA66-co-6T copolymers had both high heat resistance and good spinnability. The heat resistance and mechanical properties of the copolymer fibers were evaluated by melting and crystallization behavior of copolymers and thermal degradation kinetics. This study widens the application field of PA66 materials, especially in today's increasingly deteriorating environment, and it is of great significance to apply PA66 materials in high-temperature resistant filtration equipment of coal-fired power generation. ${ }^{31,32}$

\section{Methods}

\section{Materials}

PA66 salt and 1,6-diaminohexane were purchased from Pingdingshan Shenma Engineering Plastics Co. Ltd. Benzoic acid was obtained from Sinopharm Chemical Reagent Co. Ltd. Terephthalic acid was obtained from Luoyang Petrochemical Engineering Corporation Ltd/SINOPEC. Hypophosphite was obtained from Beijing Hengye Zhongyuan Chemical Co. Ltd. All of them were of commercial grade and were used as received without further purification.

\section{Preparation}

Synthesis of PA6T salts. 1 molar Terephthalic acid, 1 molar 1,6-diaminohexane and an appropriate amount of hypophosphorous acid catalyst were slowly added into a three-necked bottle containing an appropriate amount of deionized water, and were stirred mechanically at $55{ }^{\circ} \mathrm{C}$ for 1 hour under nitrogen atmosphere. The $\mathrm{pH}$ of the solution was adjusted to 7.0-7.2. PA6T crystalline salt was obtained after cooling and filtration.

Synthesis of PA66-co-PA6T. A certain ratio of polyamide 66 salt, polyamide $6 \mathrm{~T}$ salt, deionized water and $0.2 \mathrm{wt} \%$ of hypophosphorous acid catalyst were added into a reaction vessel. Then, the vessel was purged with nitrogen 3-5 times to remove air. The reaction temperature was raised to 210$230{ }^{\circ} \mathrm{C}$, the pressure was about $2.2-2.5 \mathrm{MPa}$, and the pressure holding reaction was carried out for 2.5-3 h. Then, the exhaust valve was opened. Within 2 hours, the gas in the reactor was released to normal pressure at a uniform speed and the reaction temperature was raised to $280{ }^{\circ} \mathrm{C}$. The reaction was carried out for $30 \mathrm{~min}$ under normal pressure and for 10-30 min under vacuum. Finally, nitrogen was added and the material was released under pressure The polyamide copolymers (pure PA66, PA66-10\%PA6T, and PA66-20\%PA6T) with aromatic structure

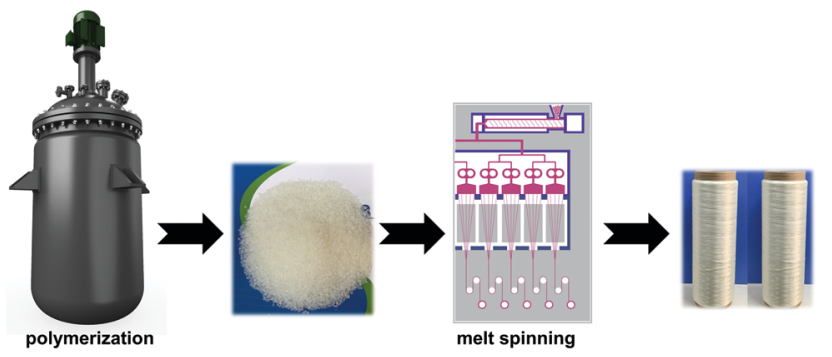

Scheme 1 Synthesis of copolymer fibers with different aromatic ring contents.

contents of $0 \mathrm{wt} \%, 10 \mathrm{wt} \%$, and $20 \mathrm{wt} \%$ were obtained after water cooling, granulation and drying.

Synthesis of fibers of PA66-co-PA6T. Different contents of PA66-co-PA6T fibers were prepared by melt spinning and multistage drawing process (showed in Scheme 1); the PA66-co-PA6T particles were melted and extruded by using a screw extruder. After mixing and homogenization, it was placed in a spinning box, measured and extruded using a metering pump. And, it went through such processes as blow cooling, oil loading, cold roll primary drawing, hot roll drawing setting and winding forming.

\section{Characterization}

Thermogravimetric analysis. The PA66-co-PA6T copolymers were examined using a thermogravimetric analyzer (TGA STA449C) from $50{ }^{\circ} \mathrm{C}$ to $600{ }^{\circ} \mathrm{C}$ at different heating rates $\left(10{ }^{\circ} \mathrm{C} \min ^{-1}, 15{ }^{\circ} \mathrm{C} \min ^{-1}, 20{ }^{\circ} \mathrm{C} \min ^{-1}\right.$ and $\left.25{ }^{\circ} \mathrm{C} \min ^{-1}\right)$ under nitrogen atmosphere.

Differential scanning calorimetric (DSC) measurements. A DSC tester (204F1) was used to analyse the melting and crystallization properties of PA66-co-PA6T samples of different components. The DSC analysis was worked at a temperature between 30 and $300{ }^{\circ} \mathrm{C}$ under the nitrogen flow of $50 \mathrm{~mL} \mathrm{~min}^{-1}$, and the heating and cooling rate was $10{ }^{\circ} \mathrm{C} \min ^{-1}$.

X-ray diffraction (XRD) analysis. The XRD analysis of the copolymers was performed using an Empyrean X-ray diffractometer with $\mathrm{CuK} \alpha$ radiations and an X'Celerator detector in the 2 Theta range from $2^{\circ}$ to $60^{\circ}$ at a scanning rate of $4^{\circ} \mathrm{min}^{-1}$. (CuK $\alpha$ : $0.154 \mathrm{~nm}$, Empyrean X-ray diffractometer).

Fiber characterization. The breaking strength of the fibers was obtained using a tensile tester at the same speed.

Mechanical properties. The mechanical properties of different components of materials tested according to ASTM standard.

FTIR characterization. The FTIR spectra of the samples were collected using a BRUKER TENSOR-27 instrument in the wavenumber range of $500-4000 \mathrm{~cm}^{-1}$.

${ }^{1}$ H-NMR characterization. The ${ }^{1} \mathrm{H}$-NMR spectrum of the copolymers was recorded in trifluoroacetic acid-D (CF3COOD) using a BRUKER AVANCE III-400 HD instrument.

SEM characterization. The SEM images were obtained using a JEOL JSM-7500F microscope. 

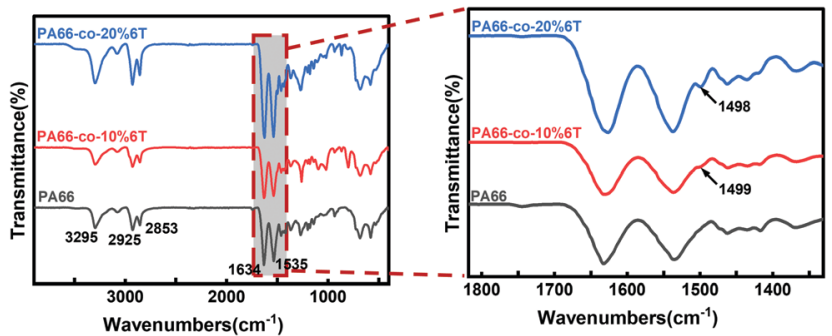

Fig. 1 FTIR of PA66 with different amounts of benzene ring.

\section{Result and discussion}

\section{FTIR and ${ }^{1} \mathrm{H}$-NMR characterization studies}

Fig. 1 shows the IR results for copolymers with different contents of $6 \mathrm{~T}$. The vibration absorption peak of benzene appears around $1500 \mathrm{~cm}^{-1}$, and the strength of this peak becomes stronger with the increase in the contents of benzene. The position located at $3295 \mathrm{~cm}^{-1}$ is assigned to the characteristic group peak of $\mathrm{C}-\mathrm{N}$ stretching vibration in amide, and $2925 \mathrm{~cm}^{-1}$ and $2853 \mathrm{~cm}^{-1}$ correspond to the stretching vibration absorption peak of $\mathrm{C}-\mathrm{H}$ of methylene. The peaks at $1634 \mathrm{~cm}^{-1}$ and $1535 \mathrm{~cm}^{-1}$ are the stretching vibration peaks of $\mathrm{C}=\mathrm{O}$ in amide and $\mathrm{C}-\mathrm{N}-\mathrm{H}$ vibration, respectively.

To further clarify the structure of the copolymers, ${ }^{1} \mathrm{H}-\mathrm{NMR}$ was carried out and the corresponding spectra are shown in Fig. 2. According to the different chemical environments, the $\mathrm{H}$ atoms in the copolymers can be roughly divided into 7 categories. Namely, the hydrogen atoms on the benzene ring, the hydrogen atoms on the carbon atoms behind the amide bond formed by the acid containing benzene ring and the aliphatic group, and the hydrogen atoms on the binary amine. Each type of hydrogen atom is assigned, and the ratio of the integral area of each part corresponds to the ratio of the number of each type of hydrogen atom.

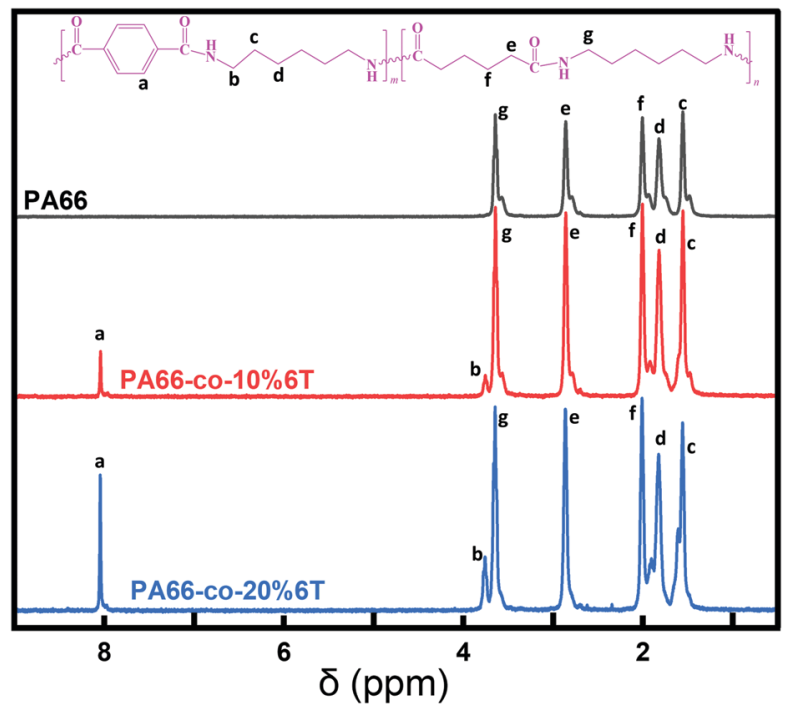

Fig. 2 1H-NMR of PA66 with different amounts of benzene ring.
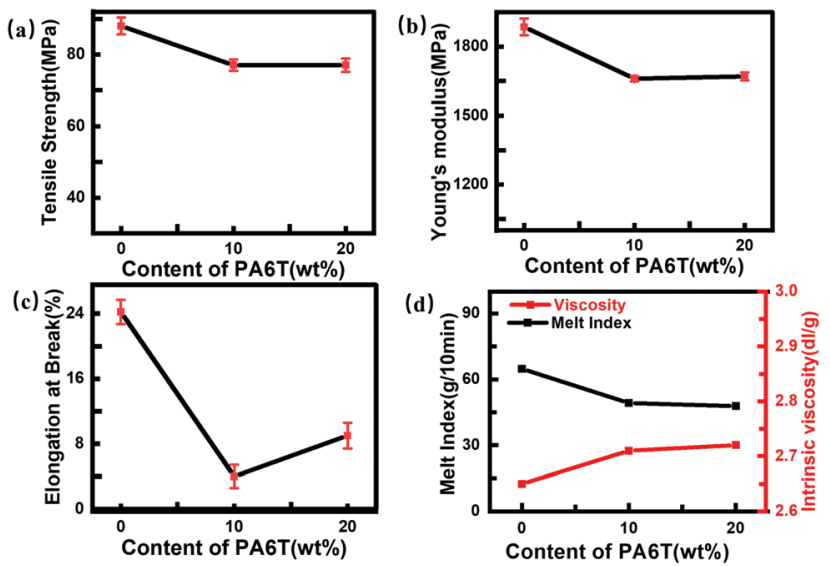

Fig. 3 Basic mechanical and flow properties of pure PA66, PA66-co10\%6T and PA66-co-20\%6T: (a) tensile strength; (b) Young's modulus; (c) elongation at break; (d) melt index and viscosity.

\section{Mechanical properties of copolymers}

Fig. 3 shows the basic mechanical properties and flowability of the materials. Molecular weight was calculated from viscosity according to the Mark-Houwink equation:

$$
[\eta]=K M_{\eta}^{\alpha}
$$

where $M_{\eta}$ is the average molecular weight and [ $\left.\eta\right]$ is the intrinsic viscosity $\left(K=2.33 \times 10^{-3} \mathrm{dl} \mathrm{g}^{-1}, \alpha=0.66\right)$. Results from the intrinsic viscosity tests of the polymers are presented in Fig. 3(d) and the average molecular weights are shown in Table 1.

From Fig. 3(a and b), it can be observed that the strength and modulus of copolymers with varying 6T contents were almost the same, only slightly lower than those of the pure PA66. The factors affecting the mechanical performance of the copolymers mainly include molecular weight (the decisive factor), the rigid benzene ring structure added to the main chain and its influence on the crystallinity. It should be noted that the molecular weights of the copolymers with different $6 \mathrm{~T}$ contents show no major changes therefore, the possible reasons for the difference in the strength and modulus of the polymers are originated from the rigid benzene ring on the main chain of polymerization, which mainly affects the intermolecular chain force and crystallinity. PA66-co-10\%6T contains less benzene ring, while it has higher crystallinity, compared with PA66-co-20\%6T. Under the combined effects of benzene ring content and crystallinity, these two copolymers show similar strength and modulus. PA66 had a larger elongation at break because it is a flexible molecular chain of aliphatic group. After a benzene ring was added, the rigidity of

Table 1 Intrinsic viscosities and $M_{\eta}$ of PA66 with different amounts of benzene ring

\begin{tabular}{llll}
\hline Samples & PA66 & PA66-co-10\%6T & PA66-co-20\%6T \\
\hline$[\eta] /\left(\mathrm{dl} \mathrm{g}^{-1}\right)$ & 2.65 & 2.71 & 2.72 \\
$M_{\eta} /\left(\mathrm{g} \mathrm{mol}^{-1}\right)$ & 42652 & 44138 & 44368
\end{tabular}



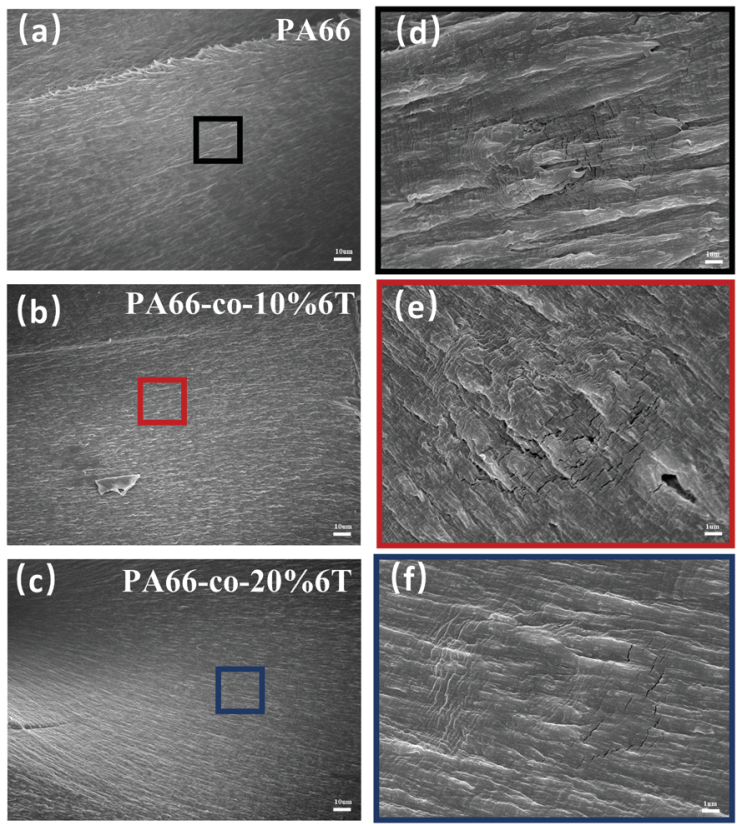

Fig. 4 SEM images of PA66 with different amounts of benzene ring: (a) PA66; (b) PA66-Co-10\%6T; (c) PA66-co-20\%6T; (d, e and f) their partial magnifications.

molecular chain increased, so the elongation of the copolymers at break decreased (Fig. 3c). Among them, PA66-co-10\%6T had a high crystallinity, so the elongation at break was the smallest, while PA66-co-20\%6T had a low crystallinity, so the elongation at break was larger than that of PA66-co-10\%6T.

We also characterized the cross section after tensile fracture (Fig. 4), and it was observed that the semi-crystalline polymer had the characteristics of ductile fracture. A ridge pattern appeared during fracture, and in the amorphous area with plastic deformation appeared tiny fiber bundles. With the increase of benzene content, the rigidity of molecular chain increased and the degree of fracture surface fluctuation decreased.

\section{The crystallization properties}

To analyse the crystalline properties of the materials, X-ray diffraction analysis was performed on the copolymers before

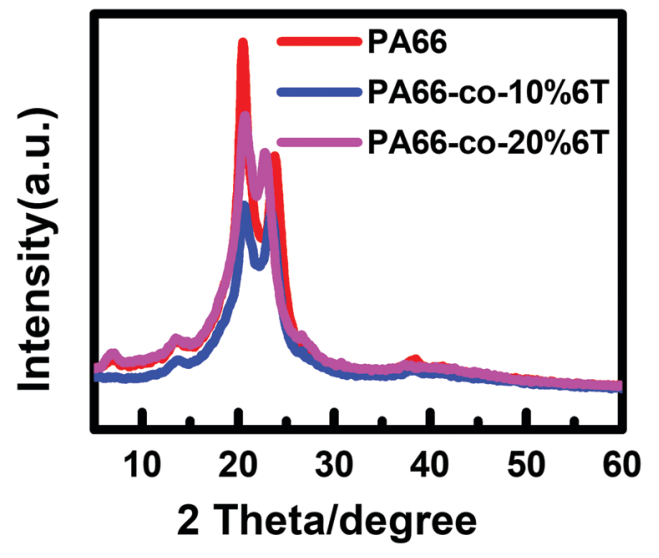

Fig. 5 XRD curve of each raw material before spinning.
Table 2 Crystallization parameters of materials before spinning

\begin{tabular}{|c|c|c|c|c|c|c|}
\hline \multirow[b]{2}{*}{$2 \theta /^{\circ}$} & \multicolumn{2}{|l|}{ PA66 } & \multicolumn{2}{|c|}{ PA66-co-10\%6T } & \multicolumn{2}{|c|}{ PA66-co-20\%6T } \\
\hline & 20.6 & 23.9 & 20.7 & 23.5 & 20.8 & 22.8 \\
\hline Grain size & 45 & 2 & 28 & 47 & 32 & 49 \\
\hline FWHM & 1.8 & 1.9 & 2.8 & 1.7 & 2.5 & 1.6 \\
\hline Peak height & 1471 & 949 & 753 & 733 & 1100 & 850 \\
\hline Peak area & 232289 & 12794 & 166538 & 117167 & 163105 & 100148 \\
\hline Relative peak area/\% & 100.0 & 54.9 & 100.0 & 70.4 & 100.0 & 61.4 \\
\hline
\end{tabular}

spinning. Fig. 5 shows the XRD curves and Table 2 shows the summary of crystal parameters after data analysis and fitting. The peak positions of PA66 are $20.3^{\circ}$ and $24.1^{\circ}, 3^{33}$ and the crystal characteristic signal peak positions of PA6T are $18.3^{\circ}$ and $23^{\circ}$. The peak positions of $2 \theta$ gradually changed from the characteristic peaks of PA66 to that of PA6T after the addition of a benzene ring. The Full Width at Half Maximum (FWHM) of PA66-co-10\%6T copolymer at about $20^{\circ}$ increased, the peak height decreased, and the grain size of the $\alpha 1$ crystal plane decreased. In addition, the relative peak area occupied by $\alpha 2$ increased, indicating that the content of $\alpha 2$ crystal increased. After adding the benzene ring, the steric hindrance increased, the intermolecular hydrogen bonding decreased, and the van der Waals force between hydrogen bonding surfaces enhanced.

Fig. 6 and Table 3 show the DSC data and the crystallinity of the copolymers. After eliminating the thermal history, the melting point $\left(T_{\mathrm{m} 2}\right)$ of pure PA66 was $262.2{ }^{\circ} \mathrm{C}$, and the $T_{\mathrm{m} 2}$ of PA66-co-20\%6T copolymer was $265.6{ }^{\circ} \mathrm{C}$, slightly higher than that of pure PA66. It is worth noting that the $T_{\mathrm{m} 2}$ of PA66-co$10 \% 6 \mathrm{~T}$ copolymer was $259.6{ }^{\circ} \mathrm{C}$, lower than that of pure PA66. And the melting temperatures of PA66, PA66-co-10\%6T and PA66-co-20\%6T ranged from 226 to $275{ }^{\circ} \mathrm{C}, 219$ to $268{ }^{\circ} \mathrm{C}$, and
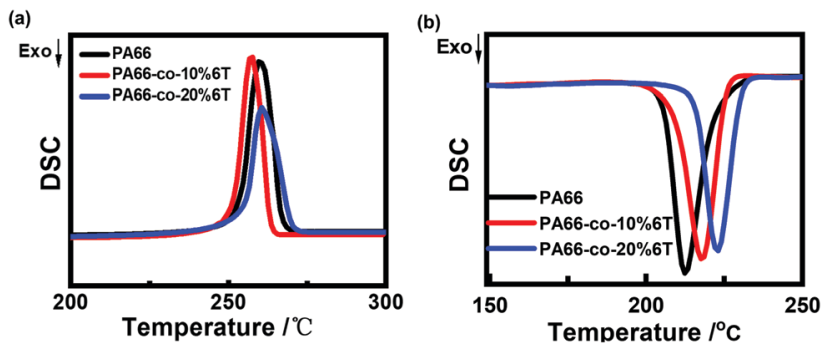

Fig. 6 Crystallization and melting behavior of pure PA66 and copolymers with different contents of PA6T: (a) the subsequent heating at a rate of $10{ }^{\circ} \mathrm{C} \mathrm{min}{ }^{-1}$; (b) first cooling.

Table 3 Summary of DSC characteristic parameters

\begin{tabular}{llll}
\hline & PA66 & PA66-co-10\%6T & PA66-co-20\%6T \\
\hline$T_{\mathrm{m} 1}\left({ }^{\circ} \mathrm{C}\right)$ & 269.4 & 263.6 & 270.4 \\
$T_{\mathrm{m} 2}\left({ }^{\circ} \mathrm{C}\right)$ & 262.2 & 259.6 & 265.6 \\
$\Delta H_{\mathrm{f} 1}\left(\mathrm{~J} \mathrm{~g}^{-1}\right)$ & 59.7 & 61.9 & 35.1 \\
$\Delta H_{\mathrm{f}}\left(\mathrm{J} \mathrm{g}^{-1}\right)$ & 28.6 & 56.7 & 54.9 \\
$\mathrm{Xc}(\%)$ & 29.2 & 28.7 & 25.4 \\
Xc-fiber $(\%)$ & 32.5 & 29.1 & 23.5 \\
$T_{\mathrm{m}}$-initial & 226 & 219 & 232 \\
$T_{\mathrm{m}}$-termination & 275 & 268 & 277
\end{tabular}



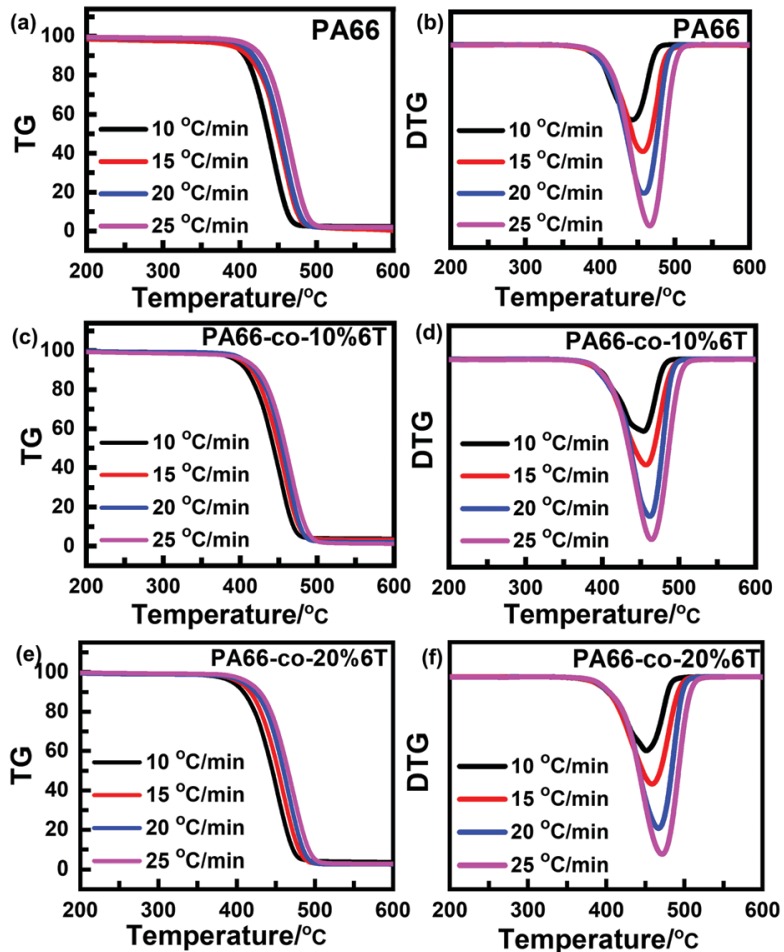

Fig. 7 Thermal stability of pure PA66 and copolymers with different contents of PA6T.

232 to $277{ }^{\circ} \mathrm{C}$, respectively. Compared with PA66, the initial melting temperature of PA66-co-10\%6T was decreased by $7{ }^{\circ} \mathrm{C}$. And the entire melt temperature range moved to a lower temperature direction, which is more conducive to melt spinning. It can also be seen that after adding the benzene ring, the crystallinity of the copolymer decreased. The crystallization properties of the copolymer decreased with the increase in benzene ring content. The crystallinity values of pure PA66, PA66-co-10\%6T and PA66-co-20\%6T were $29.2 \%, 28.7 \%$ and $25.4 \%$, respectively. Generally, on the one hand, factors that increase intermolecular forces can raise the melting point. On the other hand, increasing the intermolecular rotation resistance and reducing the number of conformation when the polymer melts also increase the melting point. After adding the benzene ring structure, a $p-\pi$ conjugate is formed, and at the same time the copolymer molecular chain conformation is reduced, leading to a higher melting point of the PA66-co-20\%6T copolymer. The melting point of PA66-co-10\%6T copolymer was lower than that of pure PA66, which was because the crystallization ability and crystallinity of the copolymer declined, resulting in its melting point decline. However, the melting point decline is more beneficial to melt spinning. ${ }^{34}$ When the content of benzene ring continued to increase, the crystallinity of the copolymer continued to decline. Meanwhile, the rigid aromatic ring structure increased the intermolecular force, resulting in the melting point of PA66-co-20\%6T copolymer being slightly higher than that of pure PA66. ${ }^{35}$

\section{Thermal properties of copolymers}

Fig. 7 shows the thermogravimetric curves of the materials before spinning under a $\mathrm{N}_{2}$ atmosphere and at different heating rates. ${ }^{36}$ It can be seen that the thermal degradation curves are smooth and all the differential $\mathrm{T}_{\mathrm{g}}$ curves are single peaks, so the thermal degradation of each material in a $\mathrm{N}_{2}$ atmosphere was a single reaction process. With the increase in heating rate, the curve moved towards high temperature, which was consistent with the random chain breaking mechanism of the polycondensation products. ${ }^{37,38}$

To exclude the influence of the heating rate on thermal degradation temperature, we obtained the relation curves of initial degradation temperature, the temperature of maximum thermal weight loss rate and termination degradation temperature with the heating rate, respectively (as shown in Fig. 8). The characteristic degradation temperatures found by extrapolating the curve to a rate of 0 are shown in Table 4.

After adding aromatic structure to PA66, the characteristic degradation temperature increased (Table 4). We focus on the initial characteristic degradation temperature $T^{0}{ }_{i}$ and the characteristic degradation temperature $T^{0}{ }_{p}$ at the maximum thermogravimetric rate. The initial characteristic degradation temperature $T^{0}{ }_{\mathrm{i}}$ values of pure PA66, PA66-co-10\%6T and PA66co-20\%6T were $359{ }^{\circ} \mathrm{C}, 369{ }^{\circ} \mathrm{C}$ and $366{ }^{\circ} \mathrm{C}$, respectively. The characteristic degradation temperature $T^{0}{ }_{\mathrm{p}}$ values at the maximum rate of thermal mass loss for pure PA66, PA66-co10\%6T and PA66-co-20\%6T were $431{ }^{\circ} \mathrm{C}, 446{ }^{\circ} \mathrm{C}$ and $436{ }^{\circ} \mathrm{C}$, respectively. In all, the PA66-co-10\%6T copolymer showed better thermal stability. (a)

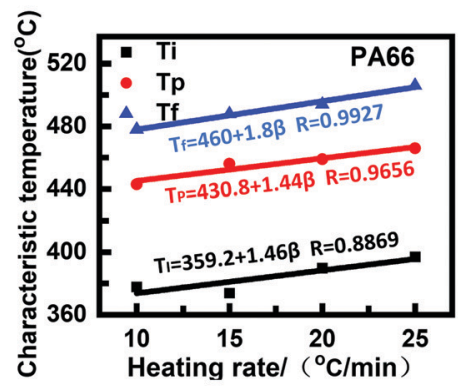

(b)

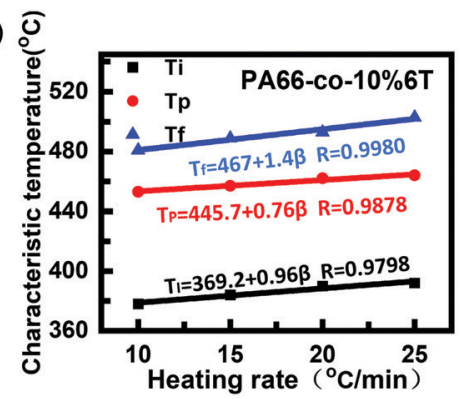

(c) 0

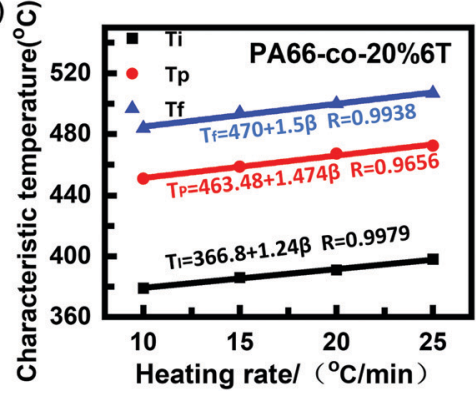

Fig. 8 Relation curve between degradation temperature and rate of raw materials before spinning: (a) PA66; (b) PA66-co-10\%6T; and (c) PA66-co$20 \% 6 \mathrm{~T}$. 
Table 4 Summary of the thermal degradation temperatures of each copolymer before spinning

\begin{tabular}{llll}
\hline & PA66 & PA66-co-10\%6T & PA66-co-20\%6T \\
\hline$T^{0}{ }_{\mathrm{i}} /{ }^{\circ} \mathrm{C}$ & 359 & 369 & 366 \\
$T^{0}{ }_{\mathrm{p}} /{ }^{\circ} \mathrm{C}$ & 431 & 446 & 436 \\
$T^{0}{ }_{\mathrm{f}} /{ }^{\circ} \mathrm{C}$ & 460 & 467 & 470
\end{tabular}

(a)

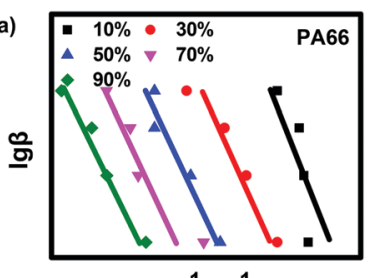

(c)

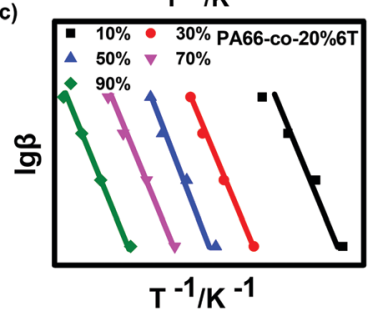

(b) $10 \% \cdot 30 \%$ PA66-co- $10 \% 6 \mathrm{~T}$
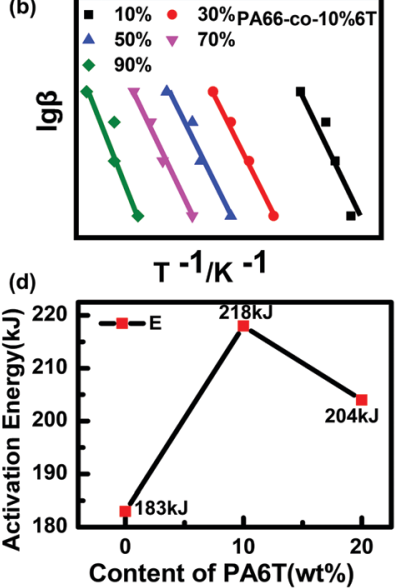

Fig. 9 Fitting curve and $E$ value obtained by the Flynn-Wall-Ozawa method of pure PA66, PA66-Co-10\%6T and PA66-co-20\%6T.

To further study the thermal degradation performance of copolymers obtained by adding the aromatic structure to PA66, the thermal degradation kinetics of copolymers was studied. The thermal degradation kinetics curves of the copolymer were obtained by the Flynn-Wall-Ozawa method (Fig. 9). ${ }^{39}$ After reading the slope of the curve for calculation, the activation energy $E$ value of thermal degradation was obtained, as shown in Fig. $7 d$.

The thermal degradation activation energy $(E)$ of the copolymers increased significantly after adding the rigid benzene ring structure, so the thermal stability of the copolymers improved significantly. Its change trend was consistent with the thermal degradation temperature.

Therefore, the thermal degradation activation energy $E$ value of PA66-co-10\%6T was the highest and this means it has better thermal stability. ${ }^{40}$

\section{The properties of fibers}

The thermal and mechanical properties of the fibers are the key factors affecting the service life. The fiber strength of the copolymers was measured at $185{ }^{\circ} \mathrm{C}$ and $200{ }^{\circ} \mathrm{C}$, respectively, and the crystallinity of polymers was calculated using eqn (2).

$$
X c=\frac{\Delta H_{\mathrm{f}}}{\Delta H_{\mathrm{f}}^{*}} \times 100 \%
$$

As shown in Fig. 10(a, b and c), the heat resistance retention rate of the benzene-containing copolymer fibers was significantly higher than that of pure PA66 after heat treatment at $185{ }^{\circ} \mathrm{C}$. The breaking strengths of PA66 fiber and PA66-co-10\%6T fiber decreased by $12.1 \%$ and $2.2 \%$, respectively. It is worth noting that the strength retention rate of PA66-co-10\%6T fiber was $100 \%$. In addition, the crystallinity values of pure PA66, PA66co-10\%6T and PA66-co-20\%6T fibers were $32.5 \%, 29.1 \%$ and $23.5 \%$, respectively (Fig. 10f). It has been reported that the heat

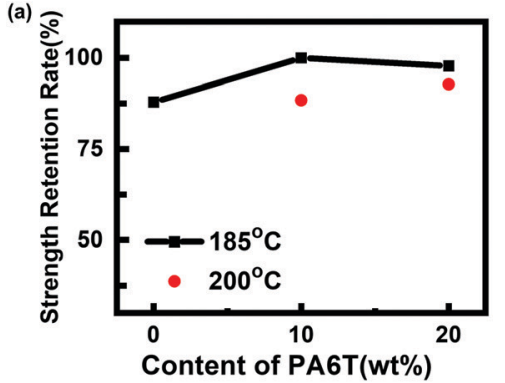

(d)

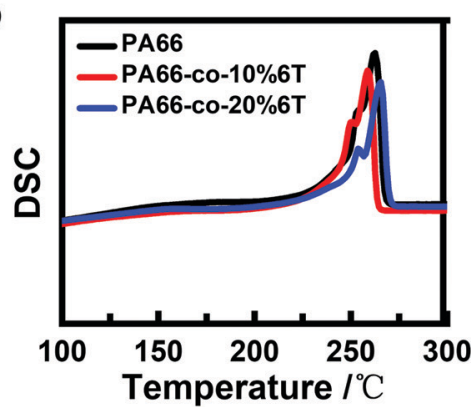

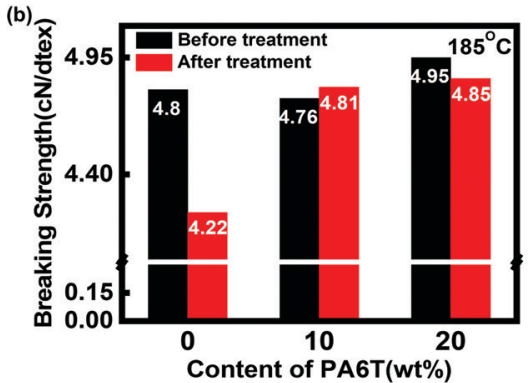

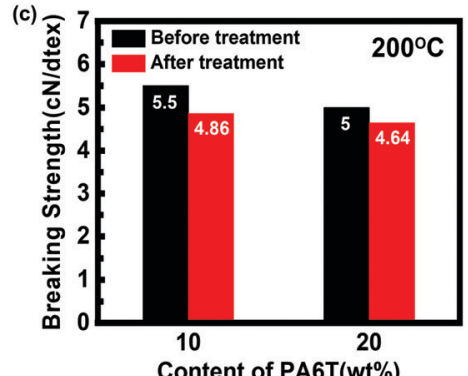

(e)
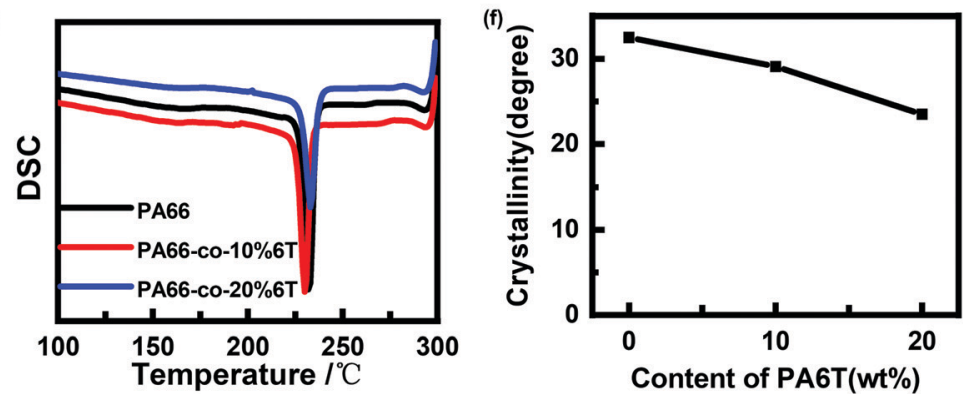

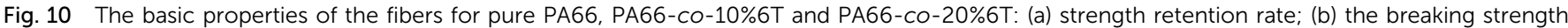

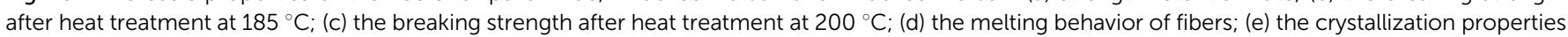
of fibers; and (f) the degree of crystallinity. 
resistance of polymers increased with the increase of crystallinity and the content of rigid components. ${ }^{41}$ Therefore, the breaking strengths of PA66-co-10\%6T fiber and PA66-co-20\%6T fiber were higher than that of the pure PA66 after heat treatment, and the breaking strength of PA66-co-20\%6T fiber was the highest. In other words, when the benzene ring content is low, it has little influence on the regularity and symmetry of the copolymer fibers, ${ }^{42}$ so less influence on the crystallization of the copolymers. A small amount of rigid benzene ring also plays a role in heat resistance, resulting in PA66-co-10\%6T with a high heat resistance strength retention rate. When the temperature increases up to $200{ }^{\circ} \mathrm{C}$, the copolymer begins to melt (shown in Fig. 10d). It is the rigid benzene ring structure that is responsible for the heat resistance. Therefore, the strength of PA66-co-10\%6T decreased, while the heat-resistant strength retention rate of PA66-co-20\% 6T fiber was still above $90 \%$ at $200{ }^{\circ} \mathrm{C}$.

\section{Conclusion}

In this paper, PA66-co-PA6T copolymers with a low content of aromatic units were prepared via copolymerization. The copolymerized fibers exhibited excellent heat resistance. The retention rates of heat resistance of fibers after heat treatment at $185{ }^{\circ} \mathrm{C}$ and $200{ }^{\circ} \mathrm{C}$ were higher than $97.8 \%$ and $88.4 \%$, respectively. By analysing the thermal properties and crystallization properties of the materials, it was found that the thermal degradation temperature and thermal degradation activation energy $(E)$ of the benzene-containing copolymers were significantly increased. The $E$ value of the PA6T-co10\%PA6T copolymer was $218 \mathrm{~kJ}$, significantly higher than that of PA66 (183 kJ). Therefore, PA66-co-PA6T copolymers with a low benzene ring content not only show excellent heat resistance, but can also realize melt spinning; its manufacturing cost is far lower than those of other currently popular hightemperature resistant filtration materials. These prominent properties expand the application range of PA66 materials, making them possible to be used as heat-resistant and hightemperature filtration materials.

\section{Conflicts of interest}

There are no conflicts to declare.

\section{Acknowledgements}

The authors thank the National Key R\&D Program of China (2016YFB0303000) and the National Natural Science Foundation of China (Grants 51803218, 51373184 and 51373179).

\section{References}

1 L. Bao, M. Musadiq, T. Kijima and K. Kenmochi, Text. Res. J., 2014, 84, 764-771.

2 W. Tanthapanichakoon, M. Furuuchi, K. H. Nitta, M. Hata and Y. Otani, Adv. Powder Technol., 2007, 18, 349-354.
3 Y. R. Lv, H. W. He, F. X. Chen, J. Yu, X. Ning and R. Zhou, Mater. Res. Express, 2019, 6, 075706.

4 H. Xu, W. Y. Jin, F. Wang, C. C. Li, J. Q. Wang, H. L. Zhu and Y. H. Guo, RSC Adv., 2018, 8, 38245-38258.

5 N. Peng, N. Widjojo, P. Sukitpaneenit, M. M. Teoh, G. G. Lipscomb, T. S. Chung and J. Y. Lai, Prog. Polym. Sci., 2012, 37, 1401-1424.

6 A. Podgorski, A. Balazy and L. Gradon, Chem. Eng. Sci., 2006, 61, 6804-6815.

7 M. H. D. A. Farahani and T.-S. Chung, Chem. Eng. J., 2018, 345, 174-185.

8 P. Marchetti, M. F. J. Solomon, G. Szekely and A. G. Livingston, Chem. Rev., 2014, 114, 10735-10806.

9 H. Kobayashi, N. Hironaka, K. Iwata, M. Hirano, M. Salvia and Y. Nishi, J. Jpn. Inst. Met., 2008, 72, 249-253.

10 W. Lyu, Y. Cui, X. Zhang, J. Yuan and W. Zhang, Des. Monomers Polym., 2016, 19, 420-428.

11 H. Wang, L. Wang, R. Wang, X. Tian and K. Zheng, Colloid Polym. Sci., 2012, 291, 1001-1007.

12 H. Gharabaghi, M. Rafizadeh and F. A. Taromi, Bull. Mater. Sci., 2016, 39, 935-941.

13 J. F. Mei Huang, J. Wang, X. Zhang, Y. Li and Y. Yan, J. Mater. Sci.: Mater. Med., 2003, 14, 655-660.

14 W. Peng, Y. Qian, T. Zhou, S. Yang, J. Jin and G. Li, Polymers, 2019, 11, 1735-1743.

15 S. Haider, A. Kausar and B. Muhammad, Polym.-Plast. Technol. Eng., 2016, 55, 1536-1556.

16 A. Ridhore and J. Jog, J. Appl. Polym. Sci., 2013, 129, 65-72. 17 J. A. Reglero Ruiz, M. Trigo-Lopez, F. C. Garcia and J. M. Garcia, Polymers, 2017, 9, 414-457.

18 J. M. Garcia, F. C. Garcia, F. Serna and J. L. de la Pena, Prog. Polym. Sci., 2010, 35, 623-686.

19 M. Hajibeygi, H. Jafarzadeh, M. Shabanian and H. Vahabi, J. Therm. Anal. Calorim., 2019, 138, 3949-3959.

20 W.-M. Peng, X. Tong, M.-L. Zhang, X.-J. Wang, G. Zhang, S.-R. Long and J. Yang, J. Appl. Polym. Sci., 2018, 135, 46451-46459.

21 K. Fuktsu, Polym. Degrad. Stab., 2002, 75, 479-484.

22 Q. Zhang, X. L. Luo, M. L. Zhang, X. J. Wang, G. Zhang, S. R. Long and J. Yang, Mater. Sci. Forum, 2015, 815, 503-508.

23 H. Wang, J. Appl. Polym. Sci., 2001, 80, 2167-2175.

24 X. Wang, Q. Zheng, L. Du and G. Yang, J. Polym. Sci., Part B: Polym. Phys., 2008, 46, 201-211.

25 Z. Wang, X. Tong, J.-C. Yang, X.-J. Wang, M.-L. Zhang, G. Zhang, S.-R. Long and J. Yang, Compos. Sci. Technol., 2019, 175, 6-17.

26 L. Qu, S.-R. Long, M.-L. Zhang, G. Zhang, X.-J. Wang and J. Yang, J. Macromol. Sci., Part A: Pure Appl. Chem., 2012, 49, 67-72.

27 J. Seo, H. Takahashi, B. Nazari, A. M. Rhoades, R. P. Schaake and R. H. Colby, Macromolecules, 2018, 51, 4269-4279.

28 J. E. Spruiell, M. D. Danford and J. L. White, J. Appl. Polym. Sci., 1978, 22, 3351-3361.

29 F. Mai, D. Pan, X. Gao, M. Yao, H. Deng, K. Wang, F. Chen and Q. Fu, Polym. Int., 2011, 60, 1646-1654. 
30 J. Zhang, X. Gao, X. Zhang, H. Liu, H. Zhang and X. Zhang, J. Mater. Sci., 2019, 54, 11056-11068.

31 Y. Wang, H. Ren, W. Liu, M. Run and H. Zhang, J. Mater. Sci., 2009, 44, 170-178.

32 K. Vijayan and A. Jain, J. Mater. Sci.: Mater. Med., 2002, 37, 2623-2633.

33 J. D. Li, Y. Zuo, X. M. Cheng, W. H. Yang, H. N. Wang and Y. B. Li, J. Mater. Sci.: Mater. Med., 2009, 20, 1031-1038.

34 Z. Cai, S. Mei, Y. Lu, Y. He, P. Pi, J. Cheng, Y. Qian and X. Wen, Int. J. Mol. Sci., 2013, 14, 20682-20691.

35 Y. Li and W. A. Goddard III, Macromolecules, 2002, 35, 8440-8455.

36 C. Leer, G. Botelho and P. Gijsman, Mater. Sci. Forum, 2004, 455, 463-466.
37 X. F. Yang, Q. L. Li, Z. P. Chen, L. Zhang and Y. Zhou, J. Therm. Anal. Calorim., 2013, 112, 567-571.

38 E. Duemichen, U. Braun, R. Kraemer, P. Deglmann and R. Senz, J. Anal. Appl. Pyrolysis, 2015, 115, 288-298.

39 X. F. Yang, Q. L. Li, Z. P. Chen, H. X. Jin and B. Liu, High Perform. Polym., 2013, 25, 502-507.

40 A. Choudhury, A. Balmurulikrishnan and G. Sarkhel, Polym. Adv. Technol., 2008, 19, 1226-1235.

41 M. Trigo-Lopez, A. Miguel-Ortega, S. Vallejos, A. Munoz, D. Izquierdo, A. Colina, F. C. Garcia and J. M. Garcia, Dyes Pigment., 2015, 122, 177-183.

42 J. B. Song, J. X. Liu, Y. H. Zhang, L. H. Chen, Y. M. Zhong and W. B. Yang, J. Compos. Mater., 2015, 49, 415-424. 